\title{
Meiotic recombination in Turnera (Turneraceae): extreme sexual difference in rates, but no evidence for recombination suppression associated with the distyly $(S)$ locus
}

\author{
JDJ Labonne, AJ Hilliker and JS Shore \\ Department of Biology, York University, Toronto, Ontario, Canada
}

\begin{abstract}
To explore the rate of recombination resulting from male vs female meiosis, crosses were performed using distylous Turnera subulata as well as a cross involving the introgression of genes from $T$. krapovickasii into $T$. subulata. We assayed four loci on the chromosome bearing the $S$-locus as well as two loci on each of two other linkage groups. Substantial and consistent dimorphism in recombination rates was found with female meiosis resulting in as much as a $\sim 6$-fold increase relative to male. Aberrant single locus segregation ratios occurred for some loci, particularly when the male (pollen) parent was heterozygous and the cross
\end{abstract}

involved introgressed genes. The extreme trend of greater recombination resulting from female meiosis was, however, maintained in crosses where no aberrant ratios occurred, indicating that the sex dimorphism in recombination is not the result of aberrant segregation. We also exploited this distylous species and tested whether there is recombination suppression around the $S$-locus because of an inversion or other chromosome rearrangement(s). We found no significant evidence for recombination suppression.

Heredity (2007) 98, 411-418; doi:10.1038/sj.hdy.6800957; published online 21 March 2007

Keywords: Turnera; distyly; meiotic recombination; recombination suppression

\section{Introduction}

Rates of recombination had been shown to vary nearly a century ago when Thomas Morgan found no evidence of crossing-over in Drosophila males, as opposed to females (Morgan, 1912). Since then, data collected on numerous dioecious and hermaphroditic species have shown that recombination rates vary from female- to male-biased in both animals (e.g., humans, Broman et al., 1998; Oncorhynchus mykiss, Sakamoto et al., 2000; Danio rerio, Singer et al., 2002; Monodelphis domestica, Samollow et al., 2004; mouse, Shifman et al., 2006) and plants (e.g., Pinus radiata, Moran et al., 1983; Arabidopsis thaliana, Vizir and Korol, 1990; Brassica oleracea, Kearsey et al., 1996; Pinus pinaster, Plomion and O'Malley, 1996). Reviews of the literature and hypotheses for recombination rate differences may be found in Bell (1982), Trivers (1988), Burt et al. (1991), Lenormand (2003), Lenormand and Dutheil (2005) and Lorch (2005).

Another kind of heterogeneity in recombination rate involves chromosome regions containing mating system loci, which have been shown to exhibit recombination suppression in a wide diversity of organisms (e.g., Ferris and Goodenough, 1994; Lee et al., 1999; Gallegos et al., 2000; Ferris et al., 2002; Wang et al., 2003). In plants, it had perhaps been first proposed that recombination suppres-

Correspondence: Dr JS Shore, Department of Biology, York University, 4700 Keele Street, Toronto, Ontario, Canada M3J 1P3.

E-mail:shore@yorku.ca

Received 25 August 2006; revised 4 December 2006; accepted 5 February 2007; published online 21 March 2007 sion might be associated with the distyly locus ( $S$-locus) in Primula (de Winton and Haldane, 1935; Mather, 1950). Distyly is a genetic polymorphism where two floral morphs (long- vs short-styled), having reciprocal arrangements of styles and stamens and commonly a selfincompatibility system, occur (Darwin, 1877). De Winton and Haldane (1935) suggested that the S-locus might be located within a small inversion in Primula sinensis that suppresses recombination. They, however, found no evidence for such suppression.

In this paper we explore the rate of meiotic recombination in a hermaphroditic outcrossing distylous species, Turnera subulata, and in a cross involving introgression of genes from distylous T. krapovickasii into T. subulata. Models and analyses by Lenormand (2003) and Lenormand and Dutheil (2005) led to the prediction that there should be a lower rate of recombination resulting from male vs female meiosis in outcrossing species. We also designed a series of controlled crosses, using genetic markers flanking the $S$-locus, to investigate whether there is recombination suppression associated with the $S$-locus because of an inversion or other chromosome rearrangement(s) in this region.

\section{Materials and methods}

\section{Recombination suppression}

To detect recombination suppression under the hypothesis that the $S$-locus is located within an inversion or other chromosome rearrangement(s), two types of controlled crosses were made in 2005. For the first, a 
heterozygous (Ss) short-styled plant of T. subulata (termed Bry) was crossed reciprocally to a homozygous (ss) long-styled plant of T. subulata (termed S16L). Progeny were grown and assayed at two isozyme loci (Pgd-c and Aco-1) that lie on opposite sides of the S-locus (Athanasiou and Shore, 1997). Genotypes of the parental plants are provided (Table 1).

The second set of reciprocal crosses was between short-styled plants of $T$. subulata homozygous for the $S$ allele and the long-styled plant used above (S16L). The short-styled plants (SS3314-1S, SS3314-8S, SS3314-9S, SS1433-24S, SS1433-28S) were constructed by exploiting the unusual self-compatible short-styled plant, Bry (Athanasiou and Shore, 1997), such that they were heterozygous at both isozyme loci (Figure 1, Table 1). All progeny were assayed for $P g d-c$ and Aco-1.

To minimize environmental effects on recombination, crosses were done at the same time using replicate rooted cuttings of all parental plants. Seeds were sown and progeny raised in the same glasshouse over the same period of time. A pilot study from a series of similar crosses was performed in 2004 using only the pollen donors (males) as the heterozygous parents.

\section{Recombination resulting from male vs female meiosis}

The crosses above (from 2005) also yield information on recombination resulting from female vs male meiosis between three loci (Aco-1, S-locus and Pgd-c). A second reciprocal cross was available to estimate differences in rates of recombination resulting from female vs male meiosis. We exploited a short-styled plant (MhBry-9S) carrying genes introgressed from T. krapovickasii into $T$. subulata (Tamari et al., 2005). The plant was crossed to S16L. We use this cross and its reciprocal (data from male meiosis were published in Athanasiou et al. (2003)), for

Table 1 Genotypes of plants used in crosses

\begin{tabular}{|c|c|c|c|c|}
\hline \multirow[t]{2}{*}{ Plant } & \multicolumn{4}{|c|}{ Locus } \\
\hline & Aco-1 & $S$ & $P g d-c$ & $T s P G$ \\
\hline \multirow[t]{2}{*}{ MhBry-9S } & Aco- $1^{S}$ & $S$ & $P g d-c^{F}$ & $T_{s} P G^{B}$ \\
\hline & $\begin{array}{l}\text { Aco- } 1^{M} \\
\text { Aco- } 1^{F}\end{array}$ & $\begin{array}{l}S^{H} \\
S\end{array}$ & $\begin{array}{l}P g d-c^{s} \\
P g d-c^{s}\end{array}$ & $\begin{array}{l}T_{s} P G^{K} \\
T_{s} P G^{B}\end{array}$ \\
\hline S16L & $\begin{array}{l}A c o-1 \\
A c o-1^{F}\end{array}$ & $s$ & $P g d-c^{s}$ & Ts $P G^{B}$ \\
\hline \multirow[t]{2}{*}{ Bry } & Aco- $1^{S}$ & $S$ & Pgd-c $c^{F}$ & \\
\hline & Aco- $1^{F}$ & $s$ & $\operatorname{Pgd} d-c^{S}$ & \\
\hline \multirow[t]{2}{*}{ SS3314-1S } & Aco- $1^{F}$ & $S$ & $P g d-c^{F}$ & \\
\hline & Aco- $1^{S}$ & $S$ & $P g d-c^{S}$ & \\
\hline \multirow[t]{2}{*}{ SS3314-8S } & Aco- ${ }^{F}$ & $S$ & $P g d-c^{F}$ & \\
\hline & Aco- $1^{S}$ & $S$ & $P g d-c^{s}$ & \\
\hline \multirow[t]{2}{*}{ SS3314-9S } & Aco- $1_{\mathrm{S}}^{F}$ & $S$ & $P g d-c_{c}^{F}$ & \\
\hline & Aco- $1^{S}$ & $S$ & $P g d-c^{s}$ & \\
\hline \multirow[t]{2}{*}{ SS1433-24S } & Aco- ${ }^{F}$ & $S$ & $P g d-c^{F}$ & \\
\hline & Aco- $1^{S}$ & $S$ & $P g d-c^{S}$ & \\
\hline \multirow[t]{2}{*}{ SS1433-28S } & Aco- ${ }^{F}$ & $S$ & $P g d-c^{F}$ & \\
\hline & Aco- $1^{S}$ & $S$ & $P g d-c^{S}$ & \\
\hline
\end{tabular}

Genotypes at the Aco-1, distyly or S-locus, $P g d-c$ and TsPG loci are provided with the linkage phases indicated on separate lines for each plant. $P g d-c^{F}$ and $P g d-c^{S}$ are alleles encoding fast- and slowmigrating allozymes of cytosolic 6-phosphogluconate dehydrogenase, $A c o-1^{F}, A c o-1^{M}$ and $A c o-1^{S}$ are alleles encoding fast-, intermediate- and slow-migrating allozymes of aconitase- $1, T s P G^{B}$ and $T s P G^{K}$ are alleles encoding a short-style-specific polygalacturonase and $S, S^{H}$ and $s$ are alleles of the distyly locus. the comparison of recombination resulting from female vs male meiosis. We assayed progeny at the Aco-1, S, $P g d-c$ and TsPG loci (Table 1). We also studied recombination among four random amplified polymorphic DNA (RAPD) loci that occur on two additional linkage groups.

\section{Isozyme and RAPD analysis}

Assays of progeny for the isozyme loci followed Shore and Barrett (1987). RAPD assays were performed using decamer primers of arbitrary sequences (Operon Technologies Inc., Alameda, CA, USA). Three primers (Opi04: $5^{\prime}$ CCGCCTAGTC; Oph06: 5' ACGCATCGCA; Opk14: 5' CCCGCTACAC) that produce markers located on two distinct linkage groups were used (Labonne and Shore, unpublished data). For the first primer, we mapped two polymorphic bands, whereas for each of the latter primers we mapped a single polymorphic band. Genomic DNA was extracted from all progeny following the protocol of Doyle and Doyle (1987) with minor modifications. RAPD-PCR was performed in a $12.5-\mu$ l reaction volume containing $\sim 50 \mathrm{ng}$ of genomic DNA, $10 \mathrm{pmol}$
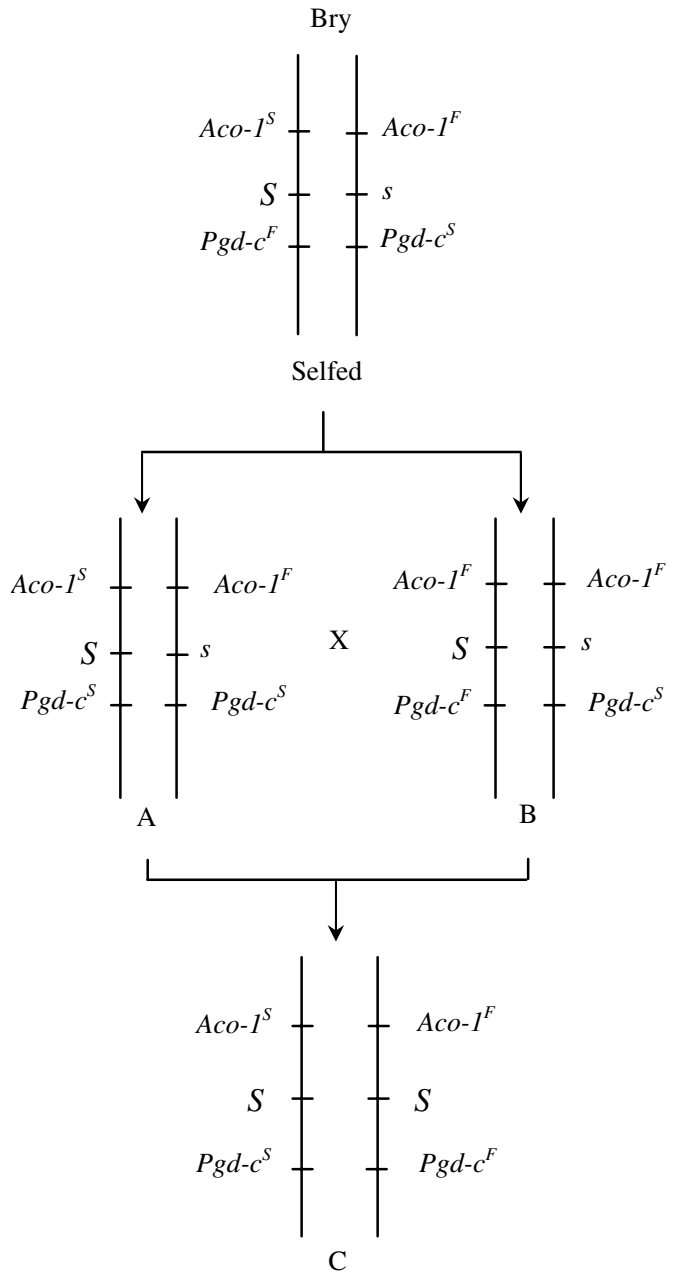

Figure 1 Crossing scheme to produce the SS-series of plants: Bry was selfed and short-styled progeny were screened to detect recombinants for one of the two isozyme loci. The Pgd-c recombinant (A) was then crossed to the Aco-1 recombinant (B) to produce homozygous (SS) plants with desired genotype (C). 
primer and JumpStart ReadyMix REDTaq DNA polymerase (Sigma-Aldrich, Oakville, ON, Canada). Amplifications were performed using a thermal cycler (Mastercycler Gradient, Eppendorf, Mississauga, ON, Canada) programmed for an initial denaturation of $2 \mathrm{~min}$ followed by 35 cycles of $94^{\circ} \mathrm{C}$ for $30 \mathrm{~s}, 37^{\circ} \mathrm{C}$ for $1 \mathrm{~min}$, $72{ }^{\circ} \mathrm{C}$ for $2 \mathrm{~min}$ and a final extension step of $72^{\circ} \mathrm{C}$ for 5 min. PCR products were run on $7.5 \%$ polyacrylamide gels, then immersed in silver nitrate solution $(0.5 \mathrm{ml}$ of $20 \% \mathrm{AgNO}_{3}$ in $50 \mathrm{ml}$ distilled water). Following five washes in distilled water, stain was developed by soaking the gels for $5-8 \mathrm{~min}$ in $\sim 30 \mathrm{ml}$ of a solution containing $16 \mathrm{~g} \mathrm{NaOH} / \mathrm{L}$ and $0.4 \%$ formaldehyde. Gels were fixed in $8 \%$ acetic acid, scored and scanned. Ambiguous samples and recombinants were rerun to verify their genotype.

\section{Statistical analyses}

We used the method of maximum likelihood to estimate recombination frequencies and their standard errors. We used the $G$ statistic (log likelihood ratio) to test for goodness of fit and/or heterogeneity among frequencies. To detect the possibility of recombination suppression, we also used Fisher's exact test (one-tailed test) as our alternative hypothesis proposes that the putative 'suppressed' crosses have a reduced recombination rate.

To investigate the ratio of recombination resulting from male vs female meiosis, we used the method of maximum likelihood to estimate recombination proportions $\left(P_{i}\right)$ using a multipoint linkage analysis. We also included one to three 'ratio' parameters $\left(R_{i}\right)$ to compare recombination resulting from male vs female meiosis. We contrasted models with different numbers of ratio parameters using the log likelihood ratio test. Maximum likelihood estimation was performed using $\mathrm{R}$ (R Development Core Team, 2004; Ricci, 2005) and MAXLIK (Reed, 1969).

We classified each backcross progeny as to whether it was non-recombinant or had recombination between the first and second loci, second and third, etc. or was a double recombinant. In the equation below, the observed numbers of various kinds of recombinant genotypes are represented as $O^{\prime}$ s for females and $M^{\prime}$ 's for males with subscripts denoting whether the recombination occurred between first and second loci, second and third loci, etc. (e.g., $M_{2}$ is number of progeny from the male cross exhibiting recombination between the second and third loci). For double recombinants, two subscripts were used to indicate the locations of recombination (e.g., $\mathrm{O}_{13}$ is the number of progeny from the female cross exhibiting recombination between the first and second loci as well as between the third and fourth loci). $O_{\text {non }}$ and $M_{\text {non }}$ are the numbers of non-recombinants from female and male meiosis, respectively. The parameters, $P_{i} \mathrm{~s}$, are the expected recombination proportions (or rates) between a pair of loci $\left(P_{\mathrm{nf}}\right.$ is the expected proportion of nonrecombinants from the female cross and $P_{\mathrm{nm}}$ is the expected proportion of non-recombinants from the male cross) and the $R_{i} \mathrm{~s}$ are the expected ratios of male to female recombination allowing a different $R_{i}$ between each adjacent pair of loci or solving for a single $R_{i}$ (setting $R_{1}=R_{2}=R_{3}$ ). As the loci used in this study had been mapped previously, we took the order as known
(Athanasiou et al., 2003; Tamari and Shore, 2006). We assumed there was no crossover interference.

We provide the $\log$ likelihood expression $(\log L)$ used for estimation, for four linked loci of known order. The constant term (const) in the expression below is a function of sample size and counts of various progeny and is not needed for estimation.

$$
\begin{aligned}
\log L= & \text { const }+\sum_{\substack{i, j, k=1 \\
i \neq j \neq k}}^{3} O_{i} \log \left(P_{i}-P_{i} P_{j}-P_{i} P_{k}\right) \\
& +\sum_{\substack{i, j=1 \\
i \neq j}}^{3} O_{i j} \log \left(P_{i} P_{j}\right)+O_{\text {non }} \log \left(P_{\mathrm{nf}}\right) \\
& +\sum_{\substack{i, j, k=1 \\
i \neq j \neq k}}^{3} M_{i} \log \left(R_{i} P_{i}-R_{i} R_{j} P_{i} P_{j}-R_{i} R_{k} P_{i} P_{k}\right) \\
& +\sum_{\substack{i, j=1 \\
i \neq j}}^{3} M_{i j} \log \left(R_{i} R_{j} P_{i} P_{j}\right)+M_{\mathrm{non}} \log \left(P_{\mathrm{nm}}\right)
\end{aligned}
$$

where

$$
\begin{gathered}
P_{\mathrm{nf}}=1-\sum_{i=1}^{3} P_{i}+\sum_{\substack{i, j=1 \\
i \neq j}}^{3} P_{i} P_{j}, \text { and } \\
P_{\mathrm{nm}}=1-\sum_{i=1}^{3} R_{i} P_{i}+\sum_{\substack{i, j=1 \\
i \neq j}}^{3} R_{i} R_{j} P_{i} P_{j}
\end{gathered}
$$

For crosses involving segregation of three linked loci, we used an analogous expression with just two recombination frequencies and two ratio parameters. For two linked loci, there is one recombination frequency and one ratio parameter.

\section{Results}

\section{Recombination suppression}

We test the hypothesis that the S-locus is located within an inversion or other chromosome rearrangement(s) that suppresses recombination in the vicinity of the $S$-locus. If the $S$-locus is located within an inversion, we expect reduced recombination for the cross of S16L $\times$ Bry compared with crosses involving the SS-series of plants. Recombination rates for crosses involving the SS-series plants in 2004, were not heterogeneous $\left(G_{\mathrm{df}=4}=9.18\right.$, $P>0.06$; Table 2). Recombination percentages for pooled data from the SS-series of crosses vs the cross of S16L $\times$ Bry were $5.35 \pm 1.30(\mathrm{cM})$ vs $3.91 \pm 1.11(\mathrm{cM})$ and were not statistically different (Fisher's exact test, $P=0.26$; Table 2).

For the 2005 data, the frequency of recombinants obtained from male meiosis involving $S S$ homozygotes was not heterogeneous $\left(G_{\mathrm{df}=1}=0.08, P>0.7\right)$. Pooled data for the $S S$ homozygotes gave a recombination percentage of $3.47 \pm 1.08(\mathrm{cM})$ vs $2.43 \pm 0.91(\mathrm{cM})$ for the cross of S16L $\times$ Bry (Fisher's exact test, $P=0.31$; Table 2). The data obtained from female meiosis involving the SS-series of plants were not significantly heterogeneous $\left(G_{\mathrm{df}=1}=3.82, P>0.05\right)$. A recombination percentage of 
$16.32 \pm 2.18(\mathrm{cM})$ obtained from the pooled data is not significantly different from $13.47 \pm 1.98$ (cM) for the cross of Bry $\times$ S16L (Fisher's exact test, $P=0.20$; Table 2).

We used all the data to explore simultaneously whether there was evidence for suppression as the increased sample size $(N=1767)$ should provide the greatest power in detecting such an effect. We used maximum likelihood estimation to estimate three parameters: the recombination rate between the $A c 0-1$ and $P g d-c$ loci, a parameter accounting for the reduced recombination of the 'suppressed' crosses and a ratio

Table 2 Comparison of recombination frequency (cM) between the Aco-1 and Pgd-c loci for crosses involving S16L $\times$ SS-series of plants, and Bry $\times$ S16L

\begin{tabular}{lrrrrr}
\hline & $\mathrm{N}$ & Non-Rec & Rec & Rec freq (s.e.) & \\
\hline Male recomb 2004 & & & & & \\
S16L $\times$ SS1433-24S & 72 & 70 & 2 & $2.78(1.94)$ & \\
S16L $\times$ SS1433-28S & 48 & 48 & 0 & $0.00(2.04)$ & \\
S16L $\times$ SS3314-1S & 71 & 67 & 4 & $5.63(2.74)$ & $G_{\text {het }}=9.18^{\mathrm{NS}}$ \\
S16L $\times$ SS3314-8S & 72 & 65 & 7 & $9.72(3.49)$ & \\
S16L $\times$ SS3314-9S & 36 & 33 & 3 & $8.33(4.61)$ & \\
POOLED & 299 & 283 & 16 & $5.35(1.30)$ & $P=0.26$ \\
S16L $\times$ Bry & 307 & 295 & 12 & $3.91(1.11)$ & \\
& & & & & \\
Male recomb 2005 & & & & & \\
S16L $\times$ SS3314-9S & 160 & 154 & 6 & $3.75(1.50)$ & $G_{\text {het }}=0.08^{\mathrm{NS}}$ \\
S16L $\times$ SS3314-1S & 128 & 124 & 4 & $3.13(1.54)$ & \\
POOLED & 288 & 278 & 10 & $3.47(1.08)$ & $P=0.31$ \\
S16L $\times$ Bry & 288 & 281 & 7 & $2.43(0.91)$ & \\
& & & & & \\
Female recomb 2005 & & & & & \\
SS3314-9S $\times$ S16L & 160 & 140 & 20 & $12.50(2.61)$ & $G_{\text {het }}=3.82^{\mathrm{NS}}$ \\
SS3314-1S $\times$ S16L & 128 & 101 & 27 & $21.09(3.61)$ & \\
POOLED & 288 & 241 & 47 & $16.32(2.18)$ & $P=0.20$ \\
Bry $\times$ S16L & 297 & 257 & 40 & $13.47(1.98)$ & \\
\hline Abbreviations: NS, not Significant; Rec, & &
\end{tabular}

Abbreviations: NS, not significant; Rec, recombination.

$G_{\text {het }}$ values compare whether the observed frequencies differ statistically. For 2004, five crosses were compared with 4 degrees of freedom. For 2005, two crosses were compared with 1 degree of freedom. The $P$-values were obtained from one-tailed Fisher's exact test comparing the pooled vs the $\mathrm{S} 16 \mathrm{~L} \times$ Bry crosses (or its reciprocal). parameter for the reduced rate of recombination resulting from male vs female meiosis (see below). Parameter estimates for this model gave a recombination percentage of $16.63 \pm 2.04(\mathrm{cM})$ resulting from female meiosis, a male to female recombination ratio of $0.26 \pm 0.02$ and a recombination suppression value of $0.79 \pm 0.02$ (a value of 1 would indicate no suppression). A model without the suppression parameter fits the data $\left(G_{\mathrm{df}=2}=2.18\right.$, $P>0.34)$ and the log likelihood ratio test for the suppression parameter indicates it is not statistically significant $\left(G_{\mathrm{df}=1}=2.03, P>0.15\right)$. Across all the data, there is no evidence for recombination suppression associated with the S-locus.

\section{Recombination resulting from male vs female meiosis}

Crosses between S16L and Bry (from 2005) provide information on recombination resulting from male vs female meiosis. The female recombination rate is significantly greater for both pairs of loci (Aco-1-S, $G_{\mathrm{df}=1}=7.22, P<0.006 ; S-P g d-c, G_{\mathrm{df}=1}=25.97, P<0.001$; Table 3).

Maximum likelihood estimation followed by a log likelihood ratio test revealed no significant difference between the ratio of recombination resulting from male vs female meiosis for the two pairs of loci $\left(G_{\mathrm{df}=1}=2.71^{\mathrm{NS}}\right)$. The model of two recombination rates and one ratio fits the data $\left(G_{\mathrm{df}=3}=2.93^{\mathrm{NS}}\right)$. The maximum likelihood estimate of the single estimated ratio of male:female recombination is $0.164 \pm 0.066$ or there is roughly a 6.1-fold increase in recombination resulting from female vs male meiosis (Table 3 ).

The reciprocal cross of S16L $\times$ MhBry-9S provides data on recombination rates for three pairs of loci (Table 3 ). The rate of recombination resulting from female meiosis was consistently and significantly greater for each locus pair ranging from about three- to sixfold greater (Table 3). Maximum likelihood estimation revealed that a single ratio is sufficient to account for the data $\left(G_{d f=2}=0.89^{N S}\right)$. The model of three recombination frequencies and one ratio fits the data $\left(G_{\mathrm{df}=8}=14.58^{\mathrm{NS}}\right)$. The maximum likelihood estimate of the single ratio of male:female recombination is $0.219 \pm 0.061$, indicating a 4.6 -fold increase for female relative to male recombination.

Table 3 Male and female recombination rates (cM) between three or four pairs of loci for two crosses

\begin{tabular}{|c|c|c|c|c|c|}
\hline \multirow[t]{2}{*}{ Cross } & \multirow[t]{2}{*}{$\mathrm{N}$} & \multicolumn{3}{|c|}{ Recombination frequency \pm s.e. (cM) } & \multirow{2}{*}{$\begin{array}{l}\text { Maximum likelihood } \\
\text { Estimate of M/F ratio }\end{array}$} \\
\hline & & Aco-1-S & $S-P g d-c$ & $P g d-c-T s P G$ & \\
\hline S16L × Bry $(M)$ & 288 & $1.74 \pm 0.77$ & $0.69 \pm 0.49$ & - & \\
\hline Bry $\times$ S16L $(F)$ & 297 & $5.72 \pm 1.35$ & $9.09 \pm 1.67$ & - & \\
\hline G & & $7.22^{* *}$ & $25.97^{* * *}$ & - & \\
\hline $\mathrm{M} / \mathrm{F}$ & & $0.303 \pm 0.152$ & $0.076 \pm 0.056$ & - & $0.164(0.066) G_{\mathrm{df}=1}=2.71^{\mathrm{NS}}$ \\
\hline S16L $\times$ MhBry-9S (M) & 169 & $3.55 \pm 1.42$ & $1.78 \pm 1.02$ & $2.96 \pm 1.30$ & \\
\hline MhBry-9S × S16L (F) & 239 & $11.72 \pm 2.08$ & $10.88 \pm 2.01$ & $15.90 \pm 2.37$ & \\
\hline G & & $9.55^{* *}$ & $28.12^{* * *}$ & $20.39^{* *}$ & \\
\hline $\mathrm{M} / \mathrm{F}$ & & $0.303 \pm 0.133$ & $0.163 \pm 0.098$ & $0.186 \pm 0.087$ & $0.219 \pm 0.061 G_{\mathrm{df}=2}=0.89^{\mathrm{NS}}$ \\
\hline
\end{tabular}

Abbreviations: M, male; F, female; $\mathrm{M} / \mathrm{F}$, ratio of male:female recombination; $\mathrm{N}$, sample size; NS, not significant.

The $\mathrm{G}$ statistic with $1 \mathrm{df}$ comparing heterogeneity in recombination rates between male vs female is provided for each locus pair.

A maximum likelihood estimate of a single male:female ratio is provided for each cross as well as a $\mathrm{G}$ statistic assessing whether it accounts for the data.

${ }^{* *} P<0.01 ;{ }^{* *} P<0.001$ 
Table 4 Male and female recombination rates \pm s.e. (cM) between Aco- 1 and Pgd-c

\begin{tabular}{lcccc}
\hline Cross & $S 16 L \times$ MhBry-9S & $S 16 L \times S S 3314-9 S$ & $S 16 L \times S S 3314-1 S$ & S16L $\times$ Bry \\
\hline M & $5.33 \pm 1.73(169)$ & $3.75 \pm 1.50(160)$ & $3.13 \pm 1.54(128)$ & $2.43 \pm 0.91(288)$ \\
F & $20.92 \pm 2.63(239)$ & $12.5 \pm 2.62(160)$ & $21.09 \pm 3.61(128)$ & $13.47 \pm 1.98(297)$ \\
M/F & $0.25 \pm 0.09$ & $0.30 \pm 0.14$ & $0.15 \pm 0.08$ & $0.18 \pm 0.07$ \\
\hline
\end{tabular}

Abbreviations: $\mathrm{M}$, male; $\mathrm{F}$, female; $\mathrm{M} / \mathrm{F}$, ratio of male:female recombination \pm s.e.

Sample size for each cross is in parentheses.

A $\log$ likelihood ratio test indicates a single ratio fits the data, $G_{\mathrm{df}=3}=2.62^{\mathrm{NS}}$.

The maximum likelihood estimate of the male:female recombination ratio $=0.209 \pm 0.044$.

Table 5 Male and female recombination rates \pm s.e. (cM) for two pairs of RAPD loci

\begin{tabular}{lccc}
\hline Cross & $\mathrm{N}$ & Oph06a-Opi04a & Opk14a-Opi04b \\
\hline S16L $\times$ MhBry-9S (M) & 169 & $0.00 \pm 0.01$ & $1.18 \pm 0.83$ \\
MhBry-9S $\times$ S16L (F) & 239 & $3.35 \pm 1.16$ & $7.53 \pm 1.71$ \\
M/F & & - & $0.16 \pm 0.12$ \\
G & & $8.7^{* *}$ & $10.2^{* *}$ \\
\hline
\end{tabular}

Abbreviations: $\mathrm{M} / \mathrm{F}$, ratio of male:female recombination; $\mathrm{N}$, sample size; RAPD, random amplified polymorphic DNA.

The $G$ statistic with $1 \mathrm{df}$ comparing heterogeneity in recombination rates between male vs female is provided for each locus pair. $* * P<0.01$

For the isozyme loci, Aco-1 and Pgd-c, data on recombination rates are available for four reciprocal crosses (Table 4). Maximum likelihood estimation revealed no evidence of heterogeneity in the ratio of male:female recombination among the crosses $\left(G_{\mathrm{df}=3}=2.62, P>0.45\right)$ and the model with one ratio fits the data $\left(G_{\mathrm{df}=6}=11.70, P>0.06\right)$. The maximum likelihood estimate of the male:female ratio is $0.209 \pm 0.044$ or there is 4.8 times more recombination resulting from female vs male meiosis for these loci.

To determine whether greater female than male recombination occurs for loci other than those linked to the S-locus, two pairs of loci on two different linkage groups were analyzed. For two RAPD loci, Oph06a and Opi04a, the recombination percentage for male was $0.0 \pm 0.01(\mathrm{cM})$ vs $3.35 \pm 1.16(\mathrm{cM})$ for female meiosis (Table 5, $G_{\mathrm{df}=1}=8.7, P<0.003$ ). Similarly, for the locus pair Opk14a-Opi04b, recombination from male vs female meiosis varied from $1.18 \pm 0.83(\mathrm{cM})$ to $7.53 \pm 1.71(\mathrm{cM})$ (Table 5, $G_{\mathrm{df}=1}=10.2, \quad P<0.002$ ). The latter value indicates that recombination resulting from female meiosis is about six times greater than that for male and is comparable to estimates above.

Our maximum likelihood estimation assumes there is no crossover interference and this appears to be a reasonable assumption. For example, the model without interference fits the data for the cross Bry $\times$ S16L $\left(G_{\mathrm{df}=1}=0.14, P>0.70\right)$, and MhBry-9S $\times$ S16L $\left(G_{\mathrm{df}=1}=0.51, P>0.47\right)$ for estimates of recombination between $A c o-1$ and the $S$-locus and the $S$-locus and $P g d-c$.

\section{Aberrant single-locus ratios}

Aberrant ratios were observed for some loci, particularly those involving the cross S16L $\times$ MhBry-9S, where genes
Table 6 Single-locus segregation ratios for test crosses and their reciprocals

\begin{tabular}{|c|c|c|c|c|}
\hline Locus & Female heter & zyous $G$ & Male hetero & ggous G \\
\hline 1. $\mathrm{MhBr}$ & $9 S \times S 16 L$ and rec & procal $^{a}$ & & \\
\hline Aco-1 & 108 FM:131 FS & $2.22^{\mathrm{NS}}$ & 40 FM:129 FS & $49.3^{* * *}$ \\
\hline$S$-locus & 118 H:121 S & $0.04^{\mathrm{NS}}$ & 36 H:133 S & $52.9^{* * *}$ \\
\hline$P g d-c$ & 112 SS:127 FS & $0.94^{\mathrm{NS}}$ & 35 SS:134 FS & $61.8^{* * *}$ \\
\hline TsPG & $118 B K: 121 B B$ & $0.04^{\mathrm{NS}}$ & $40 B K: 129 B B$ & $49.3^{* * * *}$ \\
\hline Oph06a & $89 A a: 150 a a$ & $15.74^{* * *}$ & $46 A a: 123 a a$ & $37.6^{* * *}$ \\
\hline Opi04a & 89 Aa:150 aa & $15.74^{* * *}$ & $46 A a: 123 a a$ & $37.6^{* * *}$ \\
\hline Opi04b & $119 A a: 120 a a$ & $0.01^{\mathrm{NS}}$ & $83 A a: 86 a a$ & $0.05^{\mathrm{NS}}$ \\
\hline Opk14a & $109 A a: 130 a a$ & $1.85^{\mathrm{NS}}$ & $81 A a: 86$ aa & $0.29^{\mathrm{NS}}$ \\
\hline 2. $S S 331$ & $9 S \times S 16 L$ and $S S$ & $14-1 S_{Y}$ & $6 \mathrm{~L} \mathrm{pooled} \mathrm{and} \mathrm{rec}$ & rocal $(20$ \\
\hline Aco-1 & $144 F F: 144 F S$ & $0.00^{\mathrm{NS}}$ & $147 F F: 141 F S$ & $0.13^{\mathrm{NS}}$ \\
\hline$P g d-c$ & 139 FS:149 SS & $0.35^{\mathrm{NS}}$ & $143 F S: 145 F S$ & $0.01^{\mathrm{NS}}$ \\
\hline
\end{tabular}

Abbreviation: NS, not significant.

For $A c o-1$ and $P g d-c, F, M, S$, refer to alleles encoding fast-, intermediate- and slow-migrating allozymes. For the $S$-locus, $S$ and $\mathrm{H}$ refer to short- and homostyled morphs. For the RAPD loci, $A a$ genotypes yield an amplified PCR band, whereas aa genotypes do not have the band.

The G-statistic for goodness of fit to a 1:1 ratio with $1 \mathrm{df}$ is provided. The pooled data for the reciprocal crosses of SS3314-9S $\times$ S16L and SS3314-1S $\times$ S16L were not statistically heterogeneous for either of the loci.

${ }^{\text {a }}$ Segregation data for S16L $\times$ MhBry-9S for the first four loci were published in Athanasiou et al. (2003) and data for the S-locus for MhBry-9S $\times$ S16L were published in Tamari et al. (2005). $* * * P<0.001$

were introgressed from T. krapovickasii into T. subulata. For the latter cross, where the pollen parent is heterozygous, all but two of the eight loci show marked statistical departures from the expected 1:1 ratios (Table 6). For the reciprocal cross (MhBry-9S $\times$ S16L), only two of the eight loci show significant departures from the expected ratio. For crosses solely involving T. subulata (e.g., SS3314-9S $\times$ S16L, SS3314-1S $\times$ S16L and reciprocals, from 2005), there were no statistical departures from the expected (Table 6).

\section{Discussion}

Recombination resulting from male vs female meiosis The degree of dimorphism in recombination rate in Turnera spp. ranged from 4.6- to 6.1-fold greater for female vs male meiosis for the crosses analyzed. To our knowledge, this represents one of, if not the most extreme, difference in recombination resulting from 
female vs male meiosis in a hermaphroditic plant (Bell, 1982; Burt et al., 1991; Lenormand and Dutheil, 2005).

In $P$. sinensis, the only other distylous species to have been investigated (to our knowledge), de Winton and Haldane (1935) found no consistent difference in recombination rates. Some locus pairs showed greater recombination resulting from male vs female meiosis, whereas others showed the reverse or no difference at all (de Winton and Haldane, 1935). This is in sharp contrast to our data where the frequency of recombination resulting from female meiosis is consistently and considerably greater than male.

Sex differences in recombination rate have been shown to vary among pairs of loci within a species (e.g., de Vincente and Tanksley, 1991; Singer et al., 2002; Woram et al., 2004; Hansson et al., 2005). For example, linkage analysis in Lycopersicon peruvianum showed that although one region of the genome has a 1.6-fold difference in male vs female recombination, another has a difference of 10-fold (Ganal and Tanksley, 1996). Our analysis, however, revealed no significant variation in the ratio of recombination resulting from female vs male meiosis across all pairs of loci.

A number of studies have reported that during male meiosis, the recombination rate is lower in centromeric regions and greater towards the chromosome ends (Tanksley et al., 1992; Sakamoto et al., 2000; Singer et al., 2002; Woram et al., 2004; Shifman et al., 2006). Observations of diakinesis and first metaphase of meiosis in pollen mother cells (male meiosis) appear to reveal that chiasmata are restricted towards the chromosome ends in T. subulata and T. scabra (Shore, 1991; JS Shore, personal observations). It is therefore possible that the reduced recombination rate we have measured (i.e., for male vs female meiosis) is a function of the position of loci investigated. The study of a greater number of loci, especially those located towards the chromosome ends, might aid in clarifying whether the greater recombination in female meiosis is maintained throughout the genome.

According to models and analyses (involving differential gametophytic competition) of Lenormand (2003) and Lenormand and Dutheil (2005), outcrossers should commonly exhibit lower recombination resulting from male vs female meiosis, in contrast to selfing species. The recombination rates estimated in our study are in accordance with this prediction. Why distylous P. sinensis (de Winton and Haldane, 1935) does not show a comparably large difference in female vs male recombination is unclear. Taxa possessing both distylous (outcrossing) and homostylous (selfing) species might be ideally suited to testing this model of Lenormand (2003).

In a study of genome-wide sex differences in recombination for an interspecific cross of tomato, de Vincente and Tanksley (1991) explored whether gametic selection favoring alleles derived from the recurrent parent, might be responsible for the apparent lower recombination rate in male meiosis. Their hybrid cross does exhibit aberrant ratios at some loci. Although they could not eliminate gametic selection as a factor, there was no clear evidence that single locus gametic selection was responsible for differences in recombination rate (de Vincente and Tanksley, 1991). Aberrant segregation appears to be quite common in linkage studies, particularly those involving hybridization or introgression of genes between species (e.g., Graner et al., 1991; Jenczewski et al., 1997; Ky et al., 2000; Fishman et al., 2001; Villalta et al., 2005).

We observed a considerable number of aberrant segregations for a hybrid cross (S16L $\times$ MhBry-9S) but not for crosses involving parental plants that were purely T. subulata (Table 6; Athanasiou and Shore, 1997; Tamari and Shore, 2006). As both crosses show comparably reduced recombination resulting from male vs female meiosis, the difference in these rates cannot be attributed to aberrant segregation at single locus.

\section{Recombination suppression}

We tested the hypothesis that the S-locus is located within an inverted or rearranged chromosomal segment that suppresses recombination. Although the recombination rate around the $S$-locus obtained from $S S \times s S$ crosses (putatively 'unsuppressed cross') was greater than that for $S s \times$ ss crosses (putatively 'suppressed cross'), they were not statistically different. De Winton and Haldane (1935) also did not find any statistical evidence for recombination suppression in distylous $P$. sinensis.

It is possible that our experiment was not sufficiently powerful to detect recombination suppression. Given our sample size, we should have been able to detect a recombination rate difference of about $2.2 \mathrm{cM}$ for the pooled data (Table 2). We determined this value using Fisher's exact test and determining for increasingly more extreme tables, when we would achieve a probability less than 0.05 of obtaining these data by chance, given our sample size. If the S-locus is truly located within an inversion/rearrangement, it is possible that the inverted/rearranged chromosomal segment is small causing a low degree of recombination suppression that falls below our detection limit.

In Brassica spp., recombination suppression may occur in chromosome regions possessing the S-locus (Boyes and Nasrallah, 1993; Boyes et al., 1997; Casselman et al., 2000; Shiba et al., 2003). Using population genetic and segregation data, Kamau and Charlesworth (2005), Hagenblad et al. (2006) and Kawabe et al. (2006) found evidence for recombination suppression in a narrow region around the S-locus of Arabidopsis lyrata (Brassicaceae). Once the $S$-locus gene(s) in T. subulata are discovered, it might then be possible to use these methods to explore whether recombination suppression indeed occurs.

\section{Acknowledgements}

We thank Alon Vaisman and Sukvinder Johal for assistance and Stephen Wright for advice. This work was funded by an NSERC grant to JSS.

\section{References}

Athanasiou A, Khosravi D, Tamari F, Shore JS (2003). Characterization and localization of short-specific polygalacturonase in distylous Turnera (Turneraceae). Am J Bot 90: 675-682.

Athanasiou A, Shore JS (1997). Morph-specific proteins in pollen and styles of distylous Turnera (Turneraceae). Genetics 146: 669-679.

Bell G (1982). The Masterpiece Of Nature: The Evolution And Genetics Of Sexuality. University of California Press: Berkeley. 
Boyes DC, Nasrallah JB (1993). Physical linkage of the SLG and $S R K$ genes at the self-incompatibility locus of Brassica oleracea. Mol Gen Genet 236: 369-373.

Boyes DC, Nasrallah ME, Vrebalov J, Nasrallah JB (1997). The self-incompatibility $(S)$ haplotypes of Brassica contain highly divergent and rearranged sequences of ancient origin. Plant Cell 9: 237-247.

Broman KW, Murray JC, Sheffield VC, White FL, Weber JL (1998). Comprehensive human genetic maps: Individual and sex-specific variation in recombination. Am J Hum Genet 63: 861-869.

Burt A, Bell G, Harvey PH (1991). Sex differences in recombination. J Evol Biol 4: 259-277.

Casselman AL, Vrebalov J, Conner JA, Singhal A, Giovannoni J, Nasrallah ME et al. (2000). Determining the physical limits of the Brassica $S$ locus by recombinational analysis. Plant Cell 12: 23-33.

Darwin C (1877). The Different Forms of Flowers on Plants of the Same Species. John Murray: London.

de Vincente MC, Tanksley SD (1991). Genome-wide reduction in recombination of backcross progeny derived from male versus female gametes in an interspecific cross of tomato. Theor Appl Genet 83: 173-178.

De Winton D, Haldane JBS (1935). The genetics of Primula sinensis III Linkage in the diploid. J Genet 31: 68-100.

Doyle JJ, Doyle JL (1987). A rapid DNA isolation procedure for small quantities of fresh leaf tissue. Phytochemical Bulletin 19: 11-15.

Ferris PJ, Armbrust EV, Goodenough UW (2002). Genetic structure of the mating-type locus of Chlamydomonas reinhardtii. Genetics 160: 181-200.

Ferris PJ, Goodenough UW (1994). The mating-type locus of Chlamydomonas reinhardtii contains highly rearranged DNA sequences. Cell 76: 1135-1145.

Fishman L, Kelly AJ, Morgan E, Willis JH (2001). A genetic map in the Mimulus guttatus species complex reveals transmission ratio distortion due to heterospecific interactions. Genetics 159: 1701-1716.

Gallegos A, Jacobson DJ, Raju NB, Skupski MP, Natvig DO (2000). Suppressed recombination and a pairing anomaly on the mating-type chromosome of Neurospora tetrasperma. Genetics 154: 623-633.

Ganal MW, Tanksley SD (1996). Recombination around the Tm2a and $M i$ resistance genes in different crosses of Lycopersicon peruvianum. Theor Appl Genet 92: 101-108.

Graner A, Jahoor A, Schondelmaier J, Siedler H, Pillen K, Fischbeck $G$ et al. (1991). Construction of an RFLP map of barley. Theor Appl Genet 83: 250-256.

Hagenblad J, Bechsgaard J, Charlesworth D (2006). Linkage disequilibrium between incompatibility locus region genes in the plant Arabidopsis lyrata. Genetics 173: 1057-1073.

Hansson B, Åkesson M, Slate J, Pemberton JM (2005). Linkage mapping reveals sex-dimorphic map distances in a passerine bird. Proc R Soc B 272: 2289-2298.

Jenczewski E, Gherardi M, Bonnin I, Prosperi JM, Olivieri I, Huguet T (1997). Insight on segregation distortions in two intraspecific crosses between annual species of Medicago (Leguminosae). Theor Appl Genet 94: 682-691.

Kamau E, Charlesworth D (2005). Balancing selection and low recombination affect diversity near the self-incompatibility loci of the plant Arabidopsis lyrata. Curr Biol 15: 17731778.

Kawabe A, Hansson B, Forrest A, Hagenblad J, Charlesworth D (2006). Comparative gene mapping in Arabidposis lyrata chromosomes 6 and 7 and $A$. thaliana chromosome IV: evolutionary history, rearrangements and local recombination rates. Genet Res (Camb) 88: 45-56.

Kearsey MJ, Ramsay LD, Jennings DE, Lydiate DJ, Bohoun EJR, Marshall DF (1996). Higher recombination frequencies in female compared to male meioses in Brassica oleracea. Theor Appl Genet 92: 363-367.
Ky CL, Barre P, Lorieux M, Trouslot P, Akaffou S, Louarn J et al. (2000). Interspecific genetic linkage map, segregation distortion and genetic conversion in coffee (Coffea sp.). Theor Appl Genet 101: 669-676.

Lee N, Bakkeren G, Wong K, Sherwood JE, Kronstad JW (1999). The mating-type and pathogenicity locus of the fungus Ustilago hordei spans a 500-kb region. Proc Nat Acad Sci USA 96: 15026-15031.

Lenormand $\mathrm{T}$ (2003). The evolution of sex dimorphism in recombination. Genetics 163: 811-822.

Lenormand T, Dutheil J (2005). Recombination difference between sexes: a role for haploid selection. PLOS Biol 3: 0396-0403.

Lorch PD (2005). Sex differences in recombination and mapping adaptations. Genetica 123: 39-47.

Mather K (1950). The genetical architecture of heterostyly in Primula sinensis. Evolution 4: 340-352.

Moran GF, Bell JC, Hilliker AJ (1983). Greater meiotic recombination in male vs female gametes in Pinus radiata. J Hered 74: 62.

Morgan TH (1912). Complete linkage in the second chromosome of the male of Drosophila. Science 36: 719-720.

Plomion C, O'Malley DM (1996). Recombination rate differences for pollen parents and seed parents in Pinus pinaster. Heredity 77: 341-350.

R Development Core Team (2004). R: A Language And Environment For Statistical Computing. R Foundation for Statistical Computing: Vienna, Austria.

Reed TE (1969). Genetic experience with a general maximum likelihood estimation program. In: Morton NE (ed). Computer Applications in Genetics. University of Hawaii Press: Honolulu. pp 27-29.

Ricci V (2005). Fitting Distributions with R. R Foundation for Statistical Computing: Vienna, Austria.

Sakamoto T, Danzmann RG, Gharbi K, Howard P, Ozaki A, Khoo SK et al. (2000). A microsatellite linkage map of rainbow trout (Oncorhynchus mykiss) characterized by large sex-specific differences in recombination rates. Genetics $\mathbf{1 5 5}$ 1331-1345.

Samollow PB, Kammerer CM, Mahaney SM, Schneider JL, Westenberger SJ, VandeBerg JL et al. (2004). First-generation linkage map of the gray, short-tailed opossum, Monodelphis domestica, reveals genome-wide reduction in female recombination rates. Genetics 166: 307-329.

Shiba H, Kenmochi M, Sugihara M, Iwano M, Kawasaki S, Suzuki G et al. (2003). Genomic organization of the $S$-locus region of Brassica. Biosci Biotechnol Biochem 67: 622-626.

Shifman S, Bell JT, Copley RR, Taylor MS, Williams RW, Mott R et al. (2006). A high-resolution single nucleotide polymorphism genetic map of the mouse genome. PloS Biology 4: e395 DOI: 10.1371 .

Shore JS (1991). Chromosomal evidence for autotetraploidy in Turnera ulmifolia. Can J Bot 69: 1302-1308.

Shore JS, Barrett SCH (1987). Inheritance of floral and isozyme polymorphisms in Turnera ulmifolia L. J Hered 78: 44-48.

Singer A, Perlman $\bar{H}$, Yan YL, Walker C, Corley-Smith G, Brandhorst $B$ et al. (2002). Sex-specific recombination rates in Zebrafish (Danio rerio). Genetics 160: 649-657.

Tamari F, Khosravi D, Hilliker AJ, Shore JS (2005). Inheritance of spontaneous mutant homostyles in Turnera subulata $\times$ krapovickasii and in autotetraploid T. scabra (Turneraceae). Heredity 94: 207-216.

Tamari F, Shore JS (2006). Allelic variation for a short-specific polygalacturonase in Turnera subulata: is it associated with the degree of self-compatibility? Int J Plant Sci 167: 125-133.

Tanksley SD, Ganal MW, Prince JP, de Vicente MC, Bonierbale MW, Broun P et al. (1992). High-density molecular linkage maps of the tomato and potato genomes. Genetics 132 $1141-1160$.

Trivers R (1988). Sex differences in rates of recombination and sexual selection. In: Michod RE, Levins BR (eds). The 
Evolution of Sex: an Examination of Current Ideas. Sinauer Associates: Sunderland. pp 270-286.

Villalta I, Reina-Sánchez A, Cuartero EA, Asins MJ (2005). Comparative microsatellite linkage analysis and genetic structure of two populations of $\mathrm{F}_{6}$ lines derived from Lycopersicon pimpinellifolium and L. cheesmanii. Theor Appl Genet 110: 881-894.

Vizir IY, Korol AB (1990). Sex difference in recombination in Arabidopsis. Heredity 65: 379-383.
Wang Y, Wang X, McCubbin AG, Kao T-h (2003). Genetic mapping and molecular characterization of the self-incompatibility (S) locus in Petunia inflata. Plant Mol Biol 53: 565-580

Woram RA, McGowan C, Stout JA, Gharbi K, Ferguson MM, Hoyheim B et al. (2004). A genetic linkage map for Arctic char (Salvelinus alpinus): evidence for higher recombination rates and segregation distortion in hybrid versus pure strain mapping parents. Genome 47: 304-315. 